\title{
Histological and Functional Studies on the Nitroxidergic Nerve Innervating Monkey Cerebral, Mesenteric and Temporal Arteries
}

\author{
Kazuhide Yoshida, Tomio Okamura and Noboru Toda* \\ Department of Pharmacology, Shiga University of Medical Sciences, Seta, Ohtsu 520-21, Japan \\ Received March 3, 1994 Accepted May 20, 1994
}

\begin{abstract}
Nitroxidergic nerves and their functional role were determined in a variety of monkey arteries. Nitric oxide synthase-immunoreactive nerve fibers innervating the monkey arterial wall were histochemically determined by the use of nitric oxide synthase antiserum. Thin nitric oxide synthaseimmunoreactive fibers were consistently found in the outer media of monkey cerebral, mesenteric and temporal arteries, in addition to many thicker fibers and nerve bundles in the adventitia. In the monkey pterygopalatine ganglion, the immunoreactivity was clearly seen in nerve cells, bundles and fibers. Helical strips of monkey arteries were exposed to the bathing media for tension recordings and were stimulated by electrical square pulses. In helical strips of the cerebral artery denuded of the endothelium, transmural electrical stimulation produced relaxations that were abolished by tetrodotoxin or $N^{G}$-nitro-L-arginine, a nitric oxide synthase inhibitor. In the monkey mesenteric and temporal arterial strips treated with $\alpha$-adrenoceptor antagonists, the relaxation caused by electrical stimulation was also abolished by the nitric oxide synthase inhibitor, and it was restored by L-arginine. Nitroxidergic perivascular nerves, histologically demonstrated, appear to play an important role in dilating the monkey cerebral artery and in counteracting a vasoconstriction associated with noradrenergic nerve activation in the mesenteric and temporal arteries.
\end{abstract}

Keywords: Nitric oxide synthase, Artery (monkey), Nitroxidergic innervation, Vasodilator nerve, Pterygopalatine ganglion

Cerebral arterial relaxations in response to nerve stimulation by electrical pulses or nicotine are nonadrenergic, noncholinergic in nature (1-3). There is substantial evidence supporting the hypothesis that nitric oxide (NO) regulates cerebroarterial function as a neurotransmitter liberated from the vasodilator nerve in humans (4), monkeys (5) and dogs (6-9). Bredt et al. have immunohistochemically demonstrated that nitric oxide synthase (NOS) is localized in the perivascular nerve and endothelium in rat cerebral arteries (10). There are some publications indicating the presence of NOS-immunoreactive nerve fibers in blood vessels of rodents $(11,12)$; however, their functional role has not been determined. Even though the localization is histologically demonstrated, it is uncertain whether the nerve actually regulates the vascular tone.

The present study was undertaken to immunohistochemically determine the innervation of NOS-immunoreactive fibers in the monkey middle cerebral, superior

\footnotetext{
* To whom correspondence should be addressed.
}

mesenteric and superficial temporal arteries and to correlate the histological findings with the mechanical response to transmural electrical stimulation or nicotine in these arteries. Functional attenuation of the NO generating system has been implicated in a number of vascular diseases, including hypertension $(13,14)$, diabetes (15) and vasospasm (16). To extrapolate the obtained results to humans, we used preparations from monkeys.

\section{MATERIALS AND METHODS}

\section{Histochemical study}

All experiments were in accordance with the guidelines on experimental animals issued by the Institute for Experimental Animals, Shiga University of Medical Sciences. Japanese monkeys (Macaca fuscata) of either sex (4- $7 \mathrm{~kg}$ body wt.) were anesthetized with intramuscular injections of ketamine $(40 \mathrm{mg} / \mathrm{kg})$ and sodium pentobarbital $(30 \mathrm{mg} / \mathrm{kg})$ and then killed by bleeding from the carotid arteries. The middle cerebral, basilar, superior mesenteric and superficial temporal arteries and the 
pterygopalatine ganglion were rapidly removed and fixed in ice-cold 0.1 M phosphate-buffered saline (PBS, $\mathrm{pH} 7.4$ ) containing $0.3 \%$ glutaraldehyde and $4 \%$ paraformaldehyde for $10 \mathrm{~min}$, and then postfixed overnight in $0.1 \mathrm{M}$ PBS with $4 \%$ paraformaldehyde followed by cryoprotection in $15 \%$ sucrose. Free-floating sections (20-micronthick) were cut on a cryostat $\left(-18^{\circ} \mathrm{C}\right.$ ) (Cryotom; Nakagawa Seisakusyo Co., Tokyo) and kept in 0.1 M PBS, containing $0.3 \%$ Triton $\mathrm{X}-100$ at $4{ }^{\circ} \mathrm{C}$ for 4 days. The specimens were exposed to affinity purified rabbit antiserum against rat cerebellum NOS $(17)(1: 300)$ in PBS with $0.3 \%$ Triton $X-100$ for 7 days at $4{ }^{\circ} \mathrm{C}$. Subsequently, biotinylated goat anti-rabbit immunoglobulin $\mathrm{G}$ antibody and avidin-biotinylated peroxidase complex (Vector Laboratories, Inc., Birlingame, CA, USA) were conjugated to the primary antibody at room temperature for $1 \mathrm{hr}$ each. Immunolabeled peroxidase was visualized by incubation at room temperature for 3 to $5 \mathrm{~min}$ with 0.56 mM 3,3'-diaminobenzidine tetrahydrochloride (Dojindo Laboratories, Kumamoto), $1.3 \mu \mathrm{M}$ hydrogen peroxide and $10 \mathrm{mM}$ nickel ammonium sulfate. The specimens were mounted onto gelatin/chrome-alum-coated glass slides. After several washes with distilled water, the sections were air-dried and cover-slipped with Entellan (Merck, Darmstadt, Germany). An almost adjacent section of each specimen was stained with both eosin and cresyl violet. The antiserum used in this study has demonstrated immunoreactivity for NOS in the perivascular nerves of rat cerebral artery (10). By Western blots, this affinity purified antiserum reacts specifically with NOS in brain extracts from rodents, guinea pigs, dogs and primates. An immunohistochemical control experiment, in which the antiserum against NOS was excluded from the reaction mixture, gave no positive staining.

\section{Functional study}

Middle cerebral, basilar, superior mesenteric and superficial temporal arteries obtained from anesthetized Japanese monkeys were helically cut into strips of approximately $20 \mathrm{~mm}$ in length. The endothelium was removed by gently rubbing the intimal surface with a cotton ball. The specimen was vertically fixed between hooks in a muscle bath containing the modified Ringer-Locke solution, which was maintained at $37 \pm 0.3{ }^{\circ} \mathrm{C}$ and aerated with a mixture of $95 \% \mathrm{O}_{2}$ and $5 \% \mathrm{CO}_{2}$. Constituents of the solution were as follows: $120 \mathrm{mM} \mathrm{NaCl}, 5.4 \mathrm{mM} \mathrm{KCl}, 2.2$ $\mathrm{mM} \mathrm{CaCl} 2,1.0 \mathrm{mM} \mathrm{MgCl}_{2}, 25.0 \mathrm{mM} \mathrm{NaHCO}$ and 5.6 $\mathrm{mM}$ dextrose. The $\mathrm{pH}$ of the solution was 7.38 to 7.41 . The hook anchoring the upper end of the strips was connected to the lever of a force-displacement transducer. The resting tension was adjusted to $1.0 \mathrm{~g}$, which is optimal for inducing the maximal contraction. Before starting the experiments, all of the strips were allowed to equili- brate for 90 to $120 \mathrm{~min}$ in the bathing media, during which time the fluid was replaced every 10 to $15 \mathrm{~min}$. Isometric mechanical responses were displayed on an ink-writing oscillograph. The contractile response to $30 \mathrm{mM} \mathrm{K}^{+}$was first obtained, and the preparations were repeatedly washed and re-equilibrated. Removal of endothelium was determined by an abolishment or a marked suppression of relaxation induced by the $\mathrm{Ca}^{2+}$ ionophore $\mathrm{A} 23187$ and histologically verified by a silver staining method. The arterial strips were placed between stimulating electrodes. The gaps between the strip and the electrodes were wide enough to allow undisturbed contraction and relaxation, but yet sufficiently narrow to stimulate intramural nerve terminals effectively. A train of $0.2-\mathrm{msec}$ (for cerebral artery) or 0.3-mses (for mesenteric and temporal arteries) square pulses of supramaximal intensity were applied transmurally at frequencies of $5 \mathrm{~Hz}$ for periods of $40 \mathrm{sec}$. The stimulus pulses were delivered by an electronic stimulator. To obtain the relaxant responses to transmural electrical stimulation or agonists, the arterial strips were partially contracted with prostaglandin $(\mathrm{PG}) \mathrm{F}_{2 \alpha}$. Papaverine $\left(10^{-4} \mathrm{M}\right)$ was added at the end of each series of experiments to obtain the maximal relaxation. Relaxation and contraction induced by transmural electrical stimulation or the agonists were expressed as values relative to the relaxations caused by $10^{-4} \mathrm{M}$ papaverine and contractions by $30 \mathrm{mM} \mathrm{K}^{-}$, respectively. The strips were treated for about $20 \mathrm{~min}$ with blocking agents, after the response to transmural electrical stimulation or agonists were determined to be reproducible.

\section{Statistics}

The results shown in the text are expressed as mean values \pm S.E. All reported $n$ values refer to the number of strips from separate monkeys studied. Tukey's test after one-way analysis of variance was used to evaluate the significance between group means.

\section{Drugs}

Drugs used were $N^{G}$-nitro-L-arginine (L-NA) and $N^{G}$ nitro-D-arginine (D-NA) (Peptide Institute Inc., Minoh); atropine sulfate (Tanabe Seiyaku Co., Osaka); nicotine, L- and D-arginine (Nacalai Tesque, Inc., Kyoto); $\mathrm{Ca}^{2+}$ ionophore A23187 (Boehringer Mannheim GmbH, Germany); timolol maleate (Banyu Co., Tokyo); phentolamine mesylate (Ciba-Geigy Ltd., Takarazuka); tetrodotoxin (Sankyo Co., Tokyo); nitroglycerin (NihonKayaku Co., Tokyo); papaverine hydrochloride (Dainippon Pharmaceutical Co., Osaka); PGF $_{2 \alpha}$ (Ono Co., Osaka) and prazosin hydrochloride (Pfizer Co., Tokyo). Responses to NO were obtained by adding the $\mathrm{pH} 2$-adjusted $\mathrm{NaNO}_{2}$ solution (18). Oxyhemoglobin (oxyHb) was prepared by the addition of a tenfold molar excess of the 
reducing agent, sodium dithionite, to a $1 \mathrm{mM}$ solution of commercial Hb (Sigma Chemical Co., St. Louis, MO, USA) in distilled water. Sodium dithionite was then removed by extensive dialysis.

\section{RESULTS}

\section{Histochemical study}

Figure 1 shows NOS-immunoreactive nerve fibers in preparations taken from the monkey middle cerebral (Fig. 1A) and mesenteric (Fig. 1C) arteries. Immunoreactive fibers ran irregularly along the arterial walls, and they sometimes formed fiber bundles. From these bundles consisting of several thick axons, thin fibers were ramified repeatedly. Occasionally, very thin fibers were found to enter into the arterial walls (Fig. 1, B and D). In arterial specimens, thick fibers were generally situated in outer layers of the adventitia. In a few cases, very thick fibers were seen in the outermost region of the blood vessels, suggesting the site of entry of the nerve supply. On the other hand, thin fibers running toward the lumen were distributed mainly in the adventitia-media boundary, which was identified by clearly different arrangements of the two layers. Much thinner fibers, if they were present, were observed in a narrow space of the media just beneath the adventitia-media boundary. These thinner fibers in the media appeared to represent the termination site of NOSpositive fibers, because no further ramifications or terminal dots were visible in other parts of the media. In this regard, the vessels innervated by NOS-immunoreactive fibers in the media include the middle cerebral, basilar, mesenteric and temporal (Fig. 2) arteries.

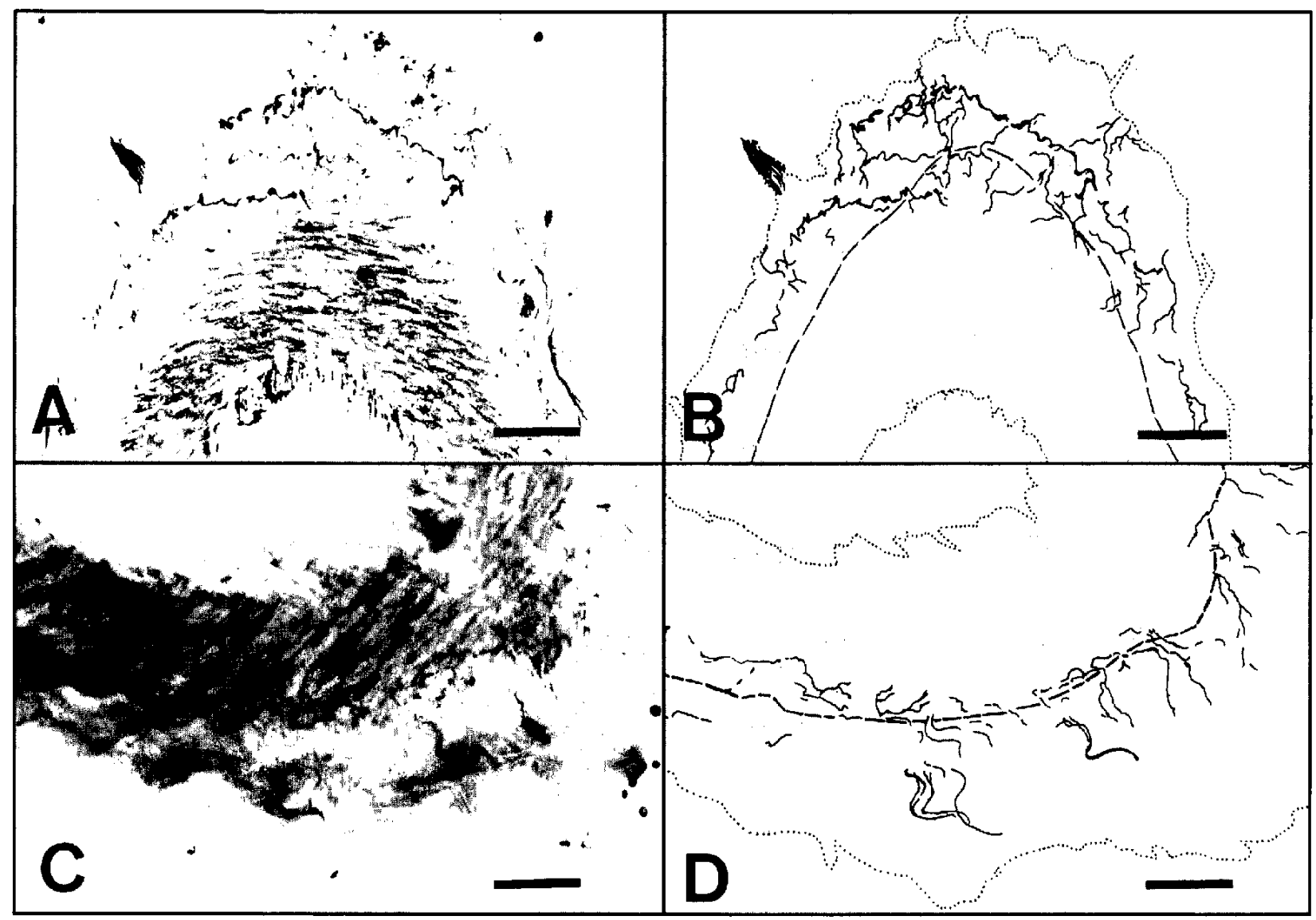

Fig. 1. Nerve fibers positively stained for NOS immunoreactivity in preparations of the monkey middle cerebral (A) and mesenteric (C) arteries which have been lightly counter-stained with eosin. Although photomicrography is not suitable to show all features of weakly stained thin fibers in thick preparations ( $A$ and $C$ ), such positive nerve fibers were traced with the help of a camera lucida drawing attachment (B and D, respectively). Thin fibers were viewed in different focal planes to achieve an accurately focused tracing of any fine fibers. These tracings were two-dimensional projections reconstructed from three-dimensional microscopic images. Medial and adventitial areas of these arteries stained with eosin were presented by light and dark gray in the black and white photomicrograph. Red blood cells stained with eosin in the arterial lumen were demonstrated to be black. In order to observe the precise locations of positive fibers in the arterial wall, these cryostat sections were cut slightly oblique to the coronal plane. Dashed lines in B and D represent the adventitia-media boundary. Bars $=50 \mu \mathrm{m}$. 
In the pterygopalatine ganglion, NOS-immunoreactivity was examined (Fig. 3). Cell bodies and nerve fibers were largely stained. The immunoreactivity was seen in large and small nerve cells and thick and fine fibers. Around the positive cells, thin axon-like fibers are densely distributed. Weak immunoreactive nerve fibers are also seen in the scattered area that contained NOS-negative

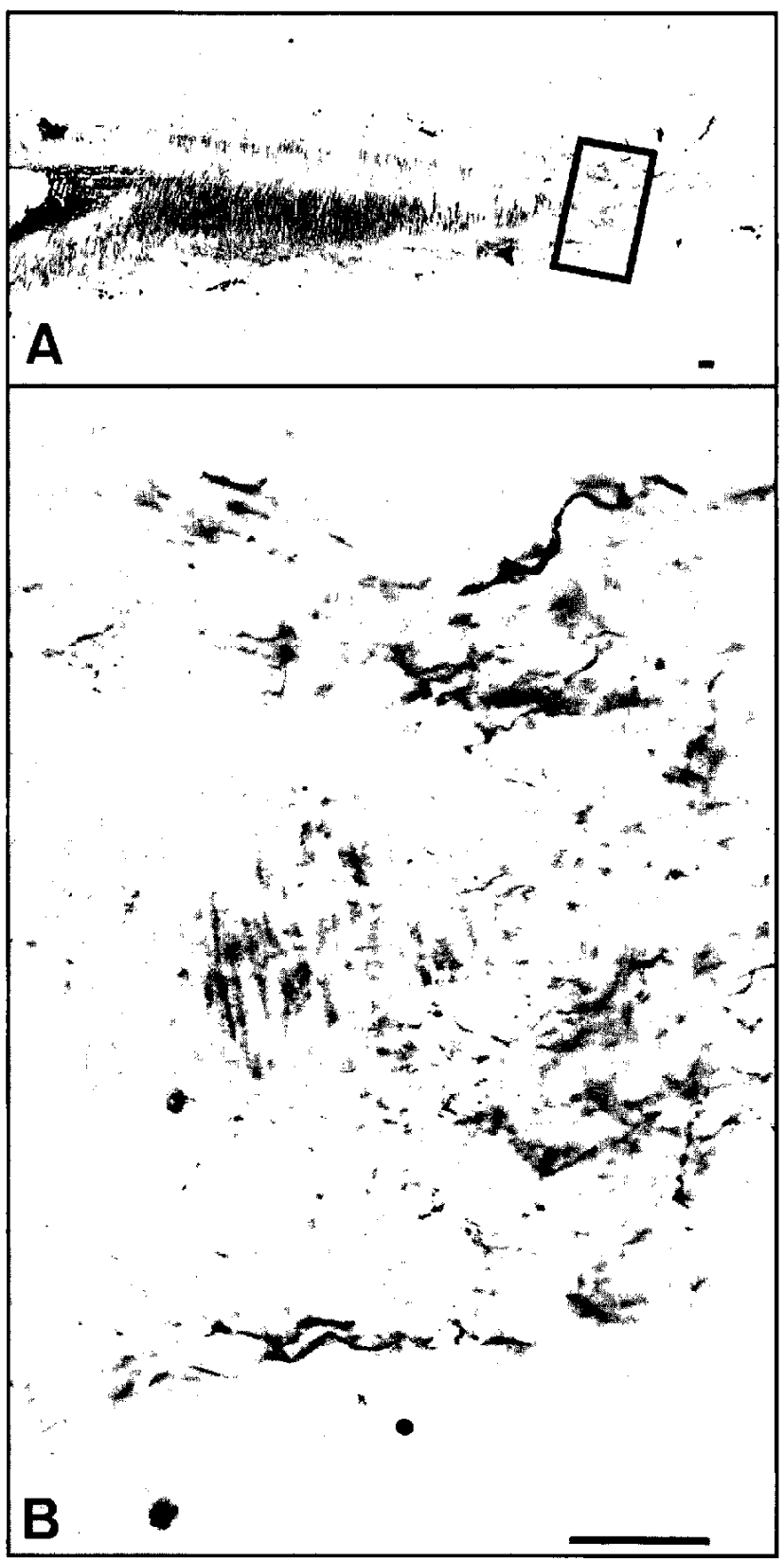

Fig. 2. Nerve fibers positively stained for NOS immunoreactivity in the monkey temporal artery which has been lightly counter-stained with eosin. Medial and adventitial areas of this artery stained with eosin are shown as light and dark gray in the black and white photomicrograph. In order to observe the precise locations of positive fibers, the cryostat section was cut oblique to the coronal plane. B shows the square area in A. Bars $=50 \mu \mathrm{m}$. stained cell bodies, when examined in a section counterstained with cresyl violet (data not shown).

\section{Functional study}

Correlation between the effectiveness of vasodilator nerve stimulation by electrical pulses or nicotine $\left(10^{-4} \mathrm{M}\right)$ and the presence of perivascular nerves containing NOSimmunoreactivity was examined.

A monkey middle cerebral arterial strip denuded of the endothelium responded to transmural electrical stimulation at $5 \mathrm{~Hz}$ with moderate relaxations that were not influenced by $10^{-7} \mathrm{M}$ timolol and $10^{-7} \mathrm{M}$ atropine (Fig. 4). Treatment with $10^{-6} \mathrm{M}$ L-NA markedly suppressed the relaxation, which was restored by the addition of L-arginine $\left(3 \times 10^{-4} \mathrm{M}\right)$. Tetrodotoxin $\left(3 \times 10^{-7} \mathrm{M}\right)$ abolished the response. These responses were obtained from the artery isolated from the same monkey used for demonstration of NOS-immunoreactive fibers (Fig. 1A). Similar results on the response to electrical stimulation and immunohistochemistry were obtained in $\mathbf{4}$ additional middle cerebral and basilar arterial strips from separate monkeys. Mean values of the relaxation before and after treatment with L-NA and $\mathrm{L}-\mathrm{NA}+\mathrm{L}$-arginine were $46.6 \pm 5.6,15.4 \pm 2.7$ and $49.0 \pm 6.8 \%(n=5, P<0.01, L-$ $\mathrm{NA}$ vs. control and L-NA $+\mathrm{L}$-arginine), respectively. Effects of L-NA and L-arginine on the arterial tone were inconsistent; no change in 3 strips and slight contraction in the remaining 2 with L-NA, and no change in 3 strips and relaxation in 2 with $\mathrm{L}$-arginine.

In the other strip from a different monkey in which NOS-positive fibers were histologically determined, the addition of nicotine, NO $\left(10^{-7} \mathrm{M}\right)$ and nitroglycerin $\left(10^{-8} \mathrm{M}\right)$ produced relaxation (Fig. 5). Treatment with $\mathrm{L}$ NA $\left(10^{-6} \mathrm{M}\right)$ abolished only the response to nicotine, but did not influence the responses to NO and nitroglycerin. The relaxant response to nicotine was reversed by repeated washing of the strip. Combined treatment with L-arginine $\left(10^{-4} \mathrm{M}\right)$ prevented the inhibitory effect of L-NA. In contrast to L-NA, the D-enantiomer did not alter the response to nicotine.

Transmural electrical stimulation $(5 \mathrm{~Hz})$ produced a contraction (Fig. 6) in a strip of the monkey mesenteric artery having NOS-immunoreactive fibers (Fig. 1C). The contraction was reversed to a relaxation by treatment with prazosin $\left(10^{-5} \mathrm{M}\right)$, which was unaffected by D-NA $\left(10^{-6} \mathrm{M}\right)$, but was abolished by L-NA $\left(10^{-6} \mathrm{M}\right)$. D-Arginine $\left(3 \times 10^{-4} \mathrm{M}\right)$ did not affect the response, but L-arginine $\left(3 \times 10^{-4} \mathrm{M}\right)$ restored the relaxant response. Atropine $\left(10^{-7} \mathrm{M}\right)$ and timolol $\left(10^{-7} \mathrm{M}\right)$ had no effect, but oxyhemoglobin $\left(1.6 \times 10^{-5} \mathrm{M}\right)$ produced a contraction. Similar data from functional and histological studies were also obtained in $\mathbf{3}$ additional strips from different monkeys. Mean values of the response in the strips treated with $10^{-5}$ 


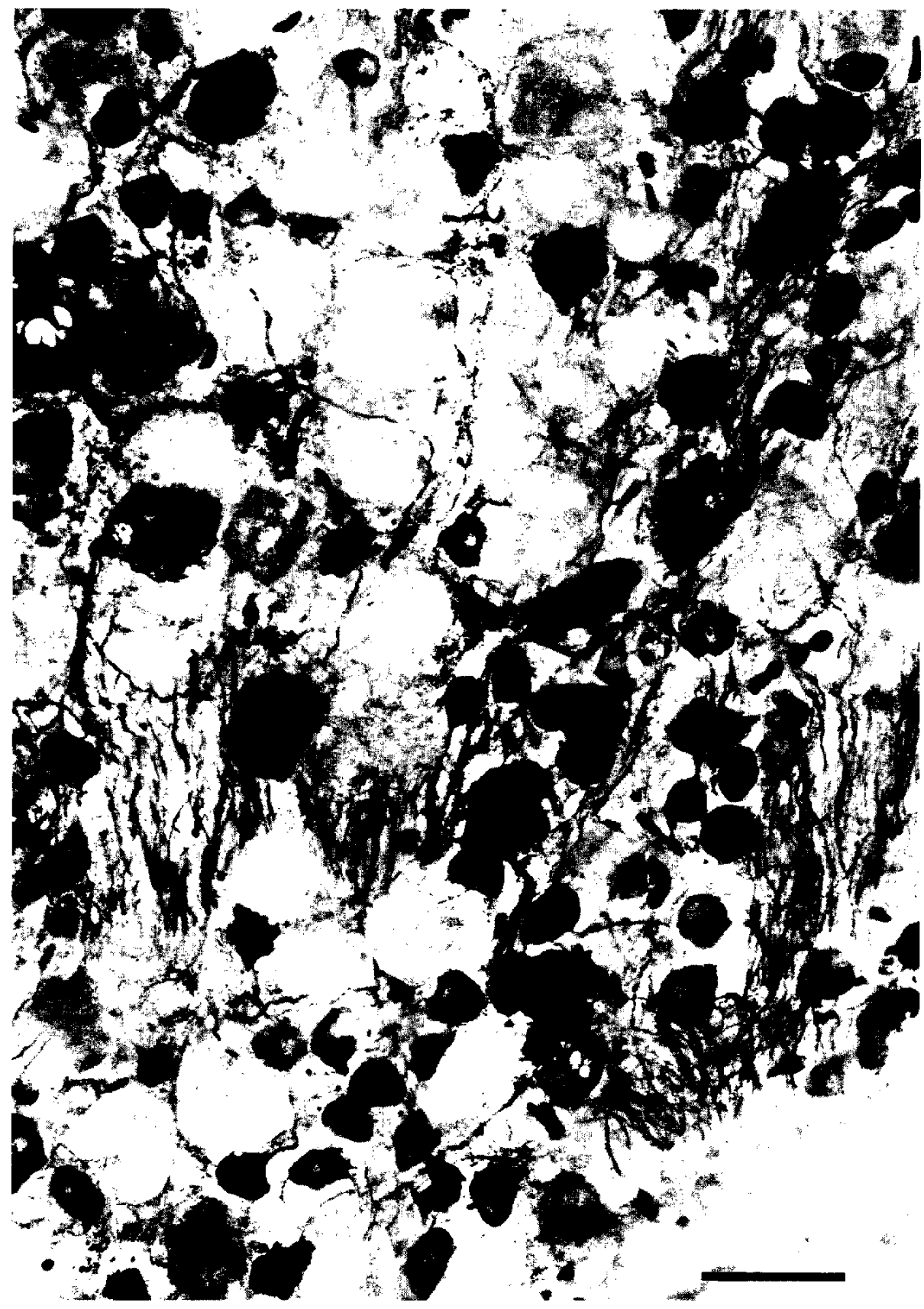

Fig. 3. Photomicrography showing NOS-immunoreactive staining in the pterygopalatine ganglion from a monkey which has been lightly counter-stained with eosin. Many intensely stained neuronal cell bodies are seen. Around the positive cells, thin axon-like fibers are densely distributed. Weak immunoreactive nerve fibers are also seen in the scattered area which may be NOSnegative stained cell bodies. When examined in a section counter-stained with cresyl violet (data not shown), over $50 \%$ of the ganglionic neurons stained positively. Bar $=50 \mu \mathrm{m}$.

$\mathrm{M}$ phentolamine or $10^{-5} \mathrm{M}$ prazosin under control conditions and treatment with L-NA and L-NA + L-arginine were $18.3 \pm 2.4$ (relaxation), $11.5 \pm 2.2$ (contraction) and $21.5 \pm 2.7 \%$ (relaxation) $(n=4, P<0.01, L-N A$ vs. control and L-NA + L-arginine), respectively.

Electrical stimulation produced a contraction of a monkey temporal arterial strip denuded of the endothelium (Fig. 7); the artery obtained from the same monkey was demonstrated to be innervated by nerve fibers containing NOS immunoreactivity (Fig. 2). The contraction was potentiated by L-NA; the potentiation was not influenced by D-arginine, but was reversed by L-arginine. After 
MONKEY MIDDLE CEREBRAL ARTERY (Rubbed) - Transmural stimulation, 5Hz

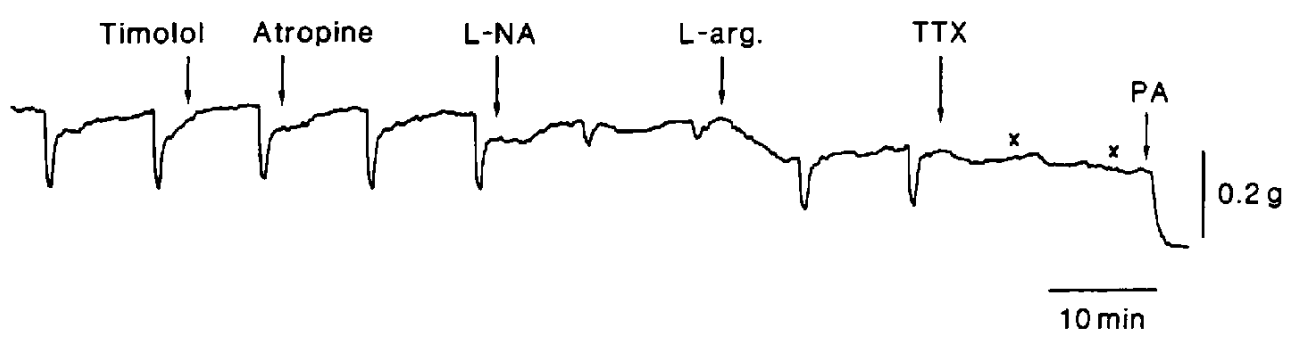

Fig. 4. Typical responses to transmural electrical stimulation $(5 \mathrm{~Hz})$ before and after treatment with timolol $\left(10^{-7} \mathrm{M}\right)$, atropine $\left(10^{-7} \mathrm{M}\right)$, L-NA $\left(10^{-6} \mathrm{M}\right)$, L-arginine (L-arg., $\left.3 \times 10^{-4} \mathrm{M}\right)$ and tetrodotoxin $\left(\mathrm{TTX}, 3 \times 10^{-7} \mathrm{M}\right.$ ) in a monkey middle cerebral arterial strip denuded of its endothelium. The strip was partially contracted with $\mathrm{PGF}_{2 \alpha}\left(10^{-7} \mathrm{M}\right)$. Papaverine (PA, $\left.10^{-4} \mathrm{M}\right)$ was used to obtain the maximal relaxation.

MONKEY CEREBRAL ARTERY - nitro-arginine (NA)

(nicotine, nitric oxide, nitroglycerin)

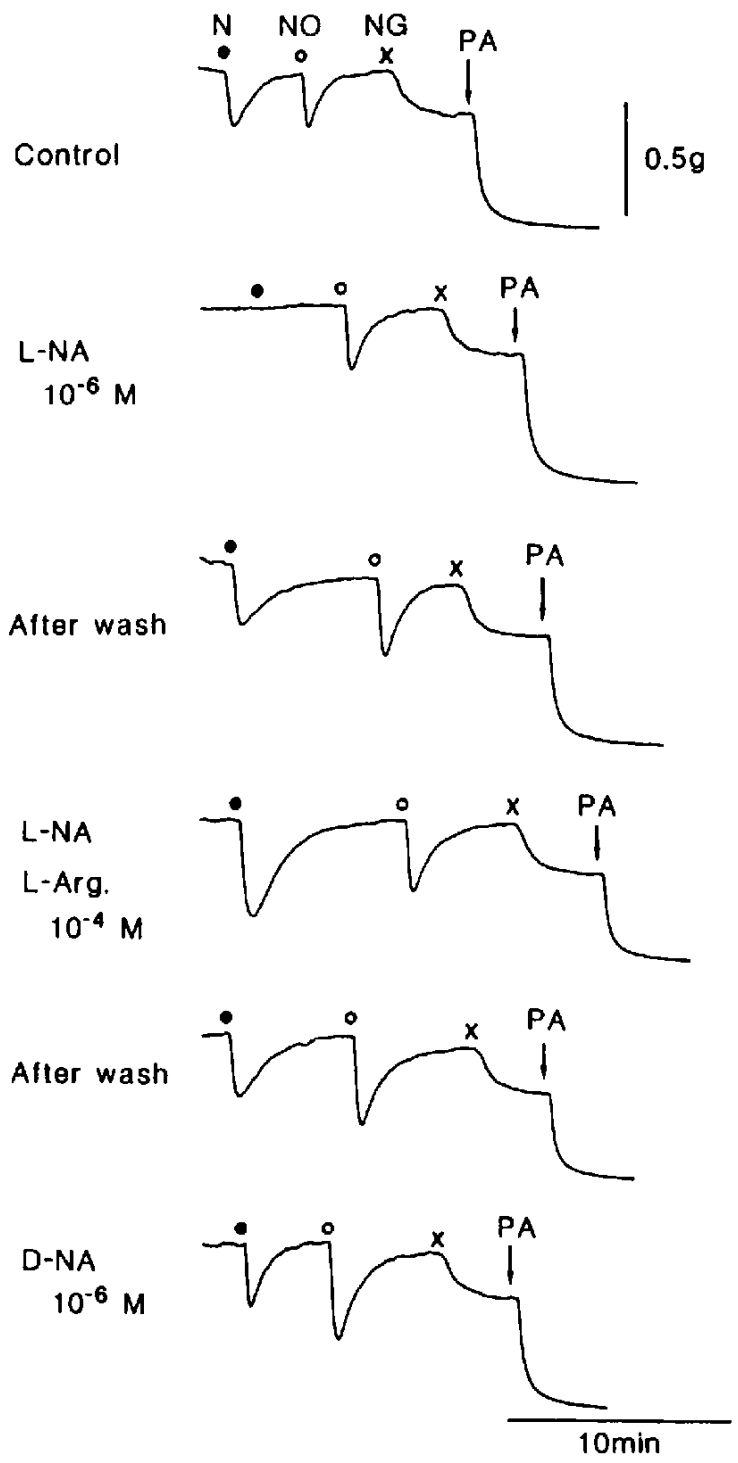

repeated rinsing, the strip treated with phentolamine $\left(10^{-5} \mathrm{M}\right)$ and partially contracted with $\mathrm{PGF}_{2 \alpha}$ responded to transmural electrical stimulation with relaxations, which were not influenced by D-NA but were abolished by L-NA. L-Arginine but not D-arginine restored the response (Fig. 7). Similar functional and histological correlation was seen in 2 additional arteries from different individuals.

\section{DISCUSSION}

The present study clearly revealed the presence of NOSimmunoreactive nerve fibers in the monkey arterial wall so far examined. These thin positive fibers are detectable in the outer media of these arteries in thin cryostat sections, showing the perivascular innervation by thin NOSpositive fibers (Figs. 1 and 2). To represent a functional significance of the innervation, the nerve distribution appears more important in the medial layer than in the adventitia, in particular where a very labile neurotransmitter, like NO, is involved. Isolated monkey cerebral arteries, denuded of the endothelium and determined to be clearly innervated by NOS-immunoreactive nerve fibers, responded to vasodilator nerve stimulation by electrical pulses (Fig. 4) and nicotine (Fig. 5) with a relaxation that was abolished by tetrodotoxin or L-NA, a NOS inhibitor. Detailed quantitative data were shown in an earlier report (5). These findings support our hypothesis (19) that nitroxidergic nerves also play an important role in dilating ar-

Fig. 5. Typical responses to nicotine $\left(\mathrm{N}, 10^{-4} \mathrm{M}\right)$, NO $\left(10^{-7} \mathrm{M}\right)$ and nitroglycerin $\left(\mathrm{NG}, 10^{-8} \mathrm{M}\right)$ before and after treatment with L-NA $\left(10^{-6}\right.$ M), L-NA + L-arginine (L-Arg., $10^{-4} \mathrm{M}$ ) and D-NA $\left(10^{-6} \mathrm{M}\right)$ in a monkey middle cerebral arterial strip denuded of its endothelium. The strip was partially contracted with $\mathrm{PGF}_{2 a}\left(2 \times 10^{-7} \mathrm{M}\right)$. Papaverine $\left(\mathrm{PA}, 10^{-4} \mathrm{M}\right)$ was used to obtain the maximal relaxation. 
MONKEY MESENTERIC ARTERY (Rubbed) - Transmural stimulation, $5 \mathrm{~Hz}$

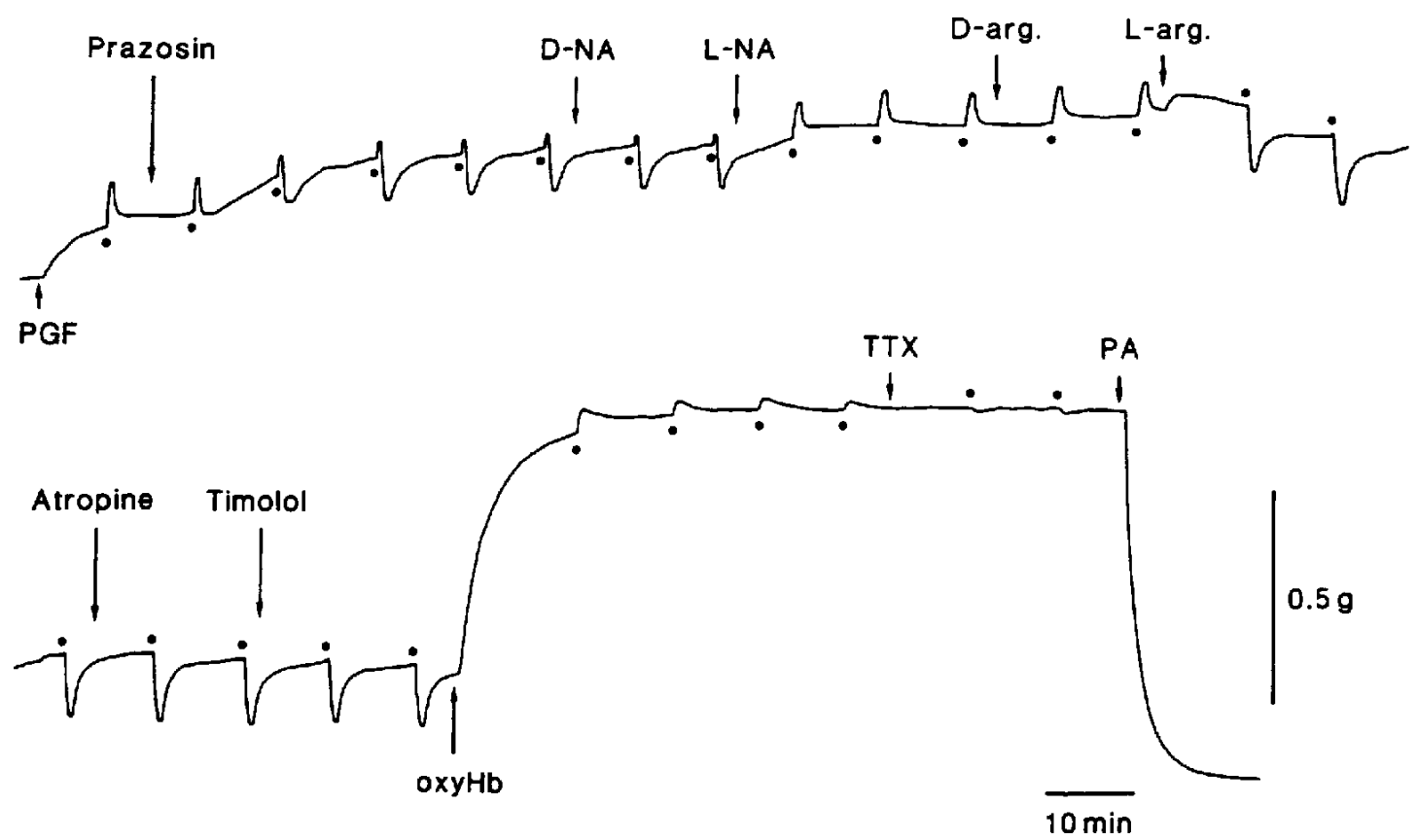

Fig. 6. Typical responses to transmural electrical stimulation $(5 \mathrm{~Hz})$ before and after treatment with prazosin $\left(10^{-5} \mathrm{M}\right)$, D-NA $\left(10^{-6} \mathrm{M}\right)$, L-NA $\left(10^{-6} \mathrm{M}\right)$, D-arginine (D-arg., $\left.3 \times 10^{-4} \mathrm{M}\right)$, L-arginine (L-arg., $\left.3 \times 10^{-4} \mathrm{M}\right)$, atropine $\left(10^{-7} \mathrm{M}\right)$, timolol $\left(10^{-7} \mathrm{M}\right)$ and oxyhemoglobin (oxyHb, $1.6 \times 10^{-5} \mathrm{M}$ ) in a monkey mesenteric arterial strip denuded of its endothelium. The strip was partially contracted with $5 \times 10^{-8} \mathrm{M} \mathrm{PGF}_{2 \alpha}$. Tetrodotoxin $(\mathrm{TTX})=3 \times 10^{-7} \mathrm{M}$; papaverine $(\mathrm{PA})=10^{-4} \mathrm{M}$.

MONKEY TEMPORAL ARTERY (Rubbed) - Transmural stimulation, $5 \mathrm{~Hz}$
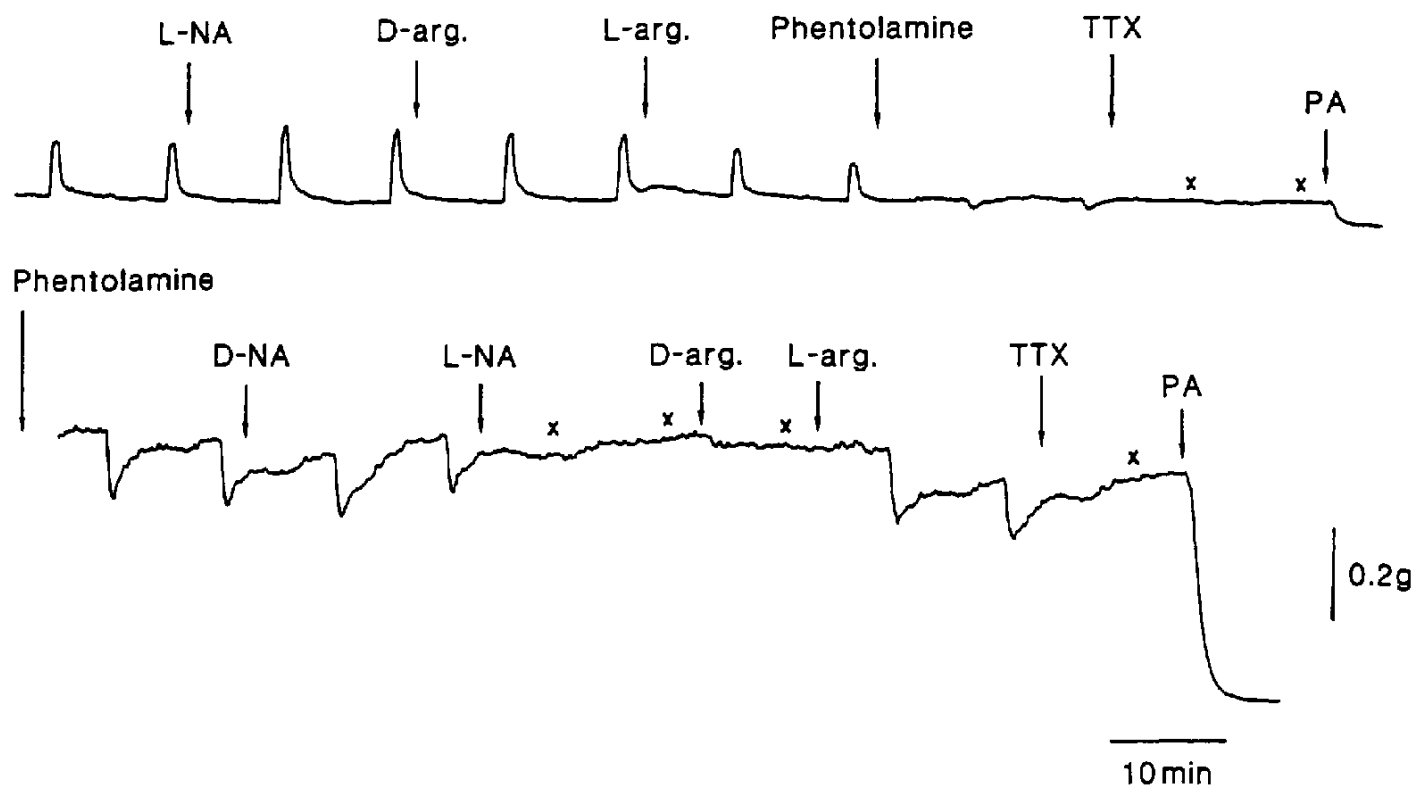

Fig. 7. Typical responses to transmural electrical stimulation $(5 \mathrm{~Hz})$ before and after treatment with L-NA $\left(10^{-6} \mathrm{M}\right)$, Darginine (D-arg., $3 \times 10^{-4} \mathrm{M}$ ) and L-arginine (L-arg., $3 \times 10^{-4} \mathrm{M}$ ) in a monkey temporal arterial strip denuded of its endothelium (top). In the same strip treated with $10^{-5} \mathrm{M}$ phentolamine (bottom), the responses to nerve stimulation were obtained before and after treatment with $\mathrm{D}$ - and L-NA $\left(10^{-6} \mathrm{M}\right)$ and $\mathrm{D}$ - and $\mathrm{L}$-arginine $\left(3 \times 10^{-4} \mathrm{M}\right)$. The strip treated with phentolamine was partially contracted with $5 \times 10^{-8} \mathrm{M} \mathrm{PGF}_{2 \alpha}$. Tetrodotoxin $(\mathrm{TTX})=3 \times 10^{-7} \mathrm{M}$; papaverine $(\mathrm{PA})=10^{-4} \mathrm{M}$. 
teries in the monkey brain.

In the monkey mesenteric and temporal arterial strips, in which fine NOS-positive fibers are distributed in the outer media, relaxation caused by transmural electrical stimulation under blockade of $\alpha$-adrenoceptors was abolished by tetrodotoxin and L-NA. The suppressed response by the NOS inhibitor was reversed by L-, but not D-, arginine. Quantitative analyses of the mechanical response have previously been reported $(20,21)$. Such a close relationship between histological demonstration of NOS-containing nerve fibers and functional response again supports the idea of nitroxidergic vasodilator innervation in monkey mesenteric and temporal arteries, which plays a role in physiologically antagonizing the vasoconstriction caused by noradrenergic nerve activation (Fig. 7) (20).

In the monkey pterygopalatine ganglion, the NOS immunoreactivity was markedly observed in nerve cells and fibers (Fig. 3). Similar findings were obtained in dogs (22) and rats (11). When examined in a section counterstained with cresyl violet, over $95 \%$ of the ganglionic neurons were stained positively in the dog pterygopalatine ganglion, whereas about $50 \%$ of the neuronal cell bodies were observed in the monkey ganglion. The monkey pterygopalatine ganglion reportedly contains a mixture of large and small myelinated as well as small unmyelinated fibers running in various directions (23). In the present study, large and small neurons seen in the ganglion were positively stained with NOS (Fig. 3), but could not functionally be discriminated. In the rat ganglion, numerous vasoactive intestinal polypeptide (VIP)-positive and cholinesterase (ChE)-containing nerve cells are recognized (24). A smaller population of NOS-positive cells in monkeys than in dogs may indicate that the relative numbers of nerve cells containing other substances relating to chemical mediators, such as VIP and acetylcholine, are greater in the monkey ganglion.

In the present study, NOS-immunoreactive nerve fibers were clearly observed in not only the adventitia but also the outer layer of the media in the monkey middle cerebral, basilar, mesenteric and temporal arteries, suggesting the involvement of the fibers in neurally-induced vasodilatation. The presence of NADPH diaphorase-containing nerves has been demonstrated between the longitudinal and circular muscle coats of the media and in the adventitia of the rabbit portal vein (25). NADPH diaphorase-containing nerves innervating blood vessels are suggested to be identical to nerves containing NOS immunoreactivity (26). The functional and histological correlation has been demonstrated in human cerebral arteries $(4,12)$. Although it is quite difficult to harvest fresh materials from humans for the functional study, the data on monkey mesenteric and temporal arteries are expected to be extrapolated to humans.

\section{Acknowledgments}

The authors thank Dr. David S. Bredt and Dr. Solomon H. Snyder (Department of Neuroscience, Johns Hopkins University, School of Medicine, Baltimore, MD, USA) for the kind gift of antiserum against rat cerebellum NOS.

\section{REFERENCES}

1 Toda N: Nicotine-induced relaxation in isolated canine cerebral arteries. J Pharmacol Exp Ther 193, 376-384 (1975)

2 Toda $\mathrm{N}$ : Non-adrenergic, non-cholinergic innervation in monkey and human cerebral arteries. Br J Pharmacol 72, 281-283 (1981)

3 Toda N: Relaxant responses to transmural stimulation and nicotine of dog and monkey cerebral arteries. Am I Physiol 243, H145-H153 (1982)

4 Toda N: Mediation by nitric oxide of neurally-induced human cerebral artery relaxation. Experientia 49, 51-53 (1993)

5 Toda $\mathrm{N}$ and Okamura T: Mechanism underlying the response to vasodilator nerve stimulation in isolated dog and monkey cerebral arteries. Am J Physiol 259, H1511-H1517 (1990)

6 Toda N, Minami $\mathrm{Y}$ and Okamura T: Inhibitory effects of $\mathrm{L}-\mathrm{N}^{\mathrm{G}}$ nitro-arginine on the synthesis of EDRF and the cerebroarteial response to vasodilator nerve stimulation. Life Sci 47, 345-351 (1990)

7 Toda $\mathrm{N}$ and Okamura T: Modification by $\mathrm{L}-N^{G}$-mono-methyl arginine (L-NMMA) of the response to nerve stimulation in isolated dog mesenteric and cerebral arteries. Jpn J Pharmacol 52, 170-173 (1990)

8 Toda $\mathrm{N}$ and Okamura $\mathrm{T}$ : Role of nitric oxide in neurally induced cerebroarterial relaxation. J Pharmacol Exp Ther 258, $1027-1032$ (1991)

9 Toda $\mathrm{N}$ and Okamura T: Possible role of nitric oxide in transmitting information from vasodilator nerve to cerebroarterial muscle. Biochem Biophys Res Commun 170, 308-313 (1990)

10 Bredt DS, Hwang PM and Snyder SH: Localization of nitric oxide synthase indicating a neural role for nitric oxide. Nature 347, 768-770 (1990)

11 Ceccatelli S, Lundberg JM, Fahrenkrug J, Bredt DS, Snyder $\mathrm{SH}$ and Hökfelt $\mathbf{T}$ : Evidence for involvement of nitric oxide in the regulation of hypothalamic portal blood flow. Neuroscience 51, 769-772 (1992)

12 Nozaki K, Moskowitz MA, Maynard KI, Koketsu N, Dawson TM, Bredt DS and Snyder SH: Possible origins and distribution of immunoreactive nitric oxide synthase-containing nerve fibers in cerebral arteries. J Cereb Blood Flow Matab 13, 70-79 (1993)

13 Dananberg J, Sider RS and Grekin RJ: Sustained hypertension induced by orally administered nitro-L-arginine. Hypertension 21, 359-363 (1993)

14 Hishikawa K, Nakaki T, Suzuki H, Kato R and Saruta T: L-Arginine as an antihypertensive agents. $\mathrm{J}$ Cardiovasc Pharmacol 20, Supp 12, S196-S197 (1992)

15 Tilton RG, Chang K, Hasan KS, Smith SR, Petrash JM, Misko TP, Moore WM, Currie MG, Corbett JA, McDaniel ML and Williamson JR: Prevention of diabetic vascular dysfunction by guanidines: Inhibition of nitric oxide synthase versus advanced glycation endproduct formation. Diabetes 42, 221-232 (1993) 
16 Katusic ZS, Milde JH, Cosentino $F$ and Mitrovic BS: Subarachnoid hemorrhage and endothelial L-arginine pathway in small brain stem arteries in dogs. Stroke 24, $392-399$ (1993)

17 Bredt DS and Snyder SH: Isolation of nitric oxide synthetase, a calmodulin-requiring enzyme. Proc Natl Acad Sci USA 87, 682-685 (1990)

18 Furchgott RF: Studies on relaxation of rabbit aorta by sodium nitrite: the basis for the proposal that the acid-activatable inhibitory factor from bovine retractor penis is inorganic nitrite and the endothelium-derived relaxing factor is nitric oxide. In Vasodilatation: Vascular Smooth Muscle, Peptides, Autonomic Nerves, and Endothelium, Edited by Vanhoutte PM, pp 401 - 414, Raven Press, New York (1988)

19 Toda $\mathrm{N}$ and Okamura T: Regulation by nitroxidergic nerve of arterial tone. News Physiol Sci 7, $148-152$ (1992)

20 Toda $\mathrm{N}$ and Okamura $\mathrm{T}$ : Reciprocal regulation by putatively nitroxidergic and adrenergic nerves of monkey and dog temporal arterial tone. Am J Physiol 261, H1740-H1745 (1991)

21 Toda $\mathrm{N}$ and Okamura $\mathrm{T}$ : Mechanism of neurally induced monkey mesenteric artery relaxation and contraction. Hyper- tension 19, $161-166$ (1992)

22 Yoshida K, Okamura T, Kimura H, Bredt DS, Snyder SH and Toda N: Nitric oxide synthase-immunoreactive nerve fibers in dog cerebral and peripheral arteries. Brain Res 629, 67-72 (1993)

23 Chorobski $\mathbf{J}$ and Penfield $\mathbf{W}$ : Cerebral vasodilator nerves and their pathway from the medulla oblongata. Arch Neurol Psychiatry 28, 1257-1289 (1932)

24 Suzuki N, Hardebo JE and Owman C: Origins and pathways of cerebrovascular vasoactive intestinal polypeptide-positive nerves in rat. J Cereb Blood Flow Matab 8, 697-712 (1988)

25 Brizzolara AL, Crowe $R$ and Burnstock G: Evidence for the involvement of both ATP and nitric oxide in non-adrenergic, non-cholinergic inhibitory neurotransmission in the rabbit portal vein. Br J Pharmacol 109, 606-608 (1993)

26 Dawson TM, Bredt DS, Fotuhi M, Hwang PM and Snyder SH: Nitric oxide synthase and neuronal NADPH diaphorase are identical in brain and peripheral tissues. Proc Natl Acad Sci USA 88, 7797-7801 (1991) 